Published by LPMP Imperium

Journal homepage: https:/ / ejournal.imperiuminstitute.org/ index.php/JMSAB

\section{Munculnya Digital Influencer Merubah Perilaku Konsumen Pada Promosi Produk, Pemilihan Produk, dan Keputusan Pembelian Generasi Milenial: Studi Pada Akun YouTube Ria SW}

\section{Grace Putlia*, Nataya Niken Thioanda}

Manajemen, Fakultas Ilmu Sosial dan Humaniora, Universitas Bunda

Mulia

\begin{abstract}
Indonesia shows a change in the behavior patterns of modern consumers who rely on social media sites to get information and reviews of desired products. In line with this, an interesting phenomenon is that after going through a pre-test, Bunda Mulia University students belonging to the millennial generation claimed that a lot of information on where to eat their destination came from digital influencers that they often watched through YouTube. Qualitative research with case study design was used as a research design. The results of the study stated that the 19 informants namely students in the millennial generation gave the same statement regarding digital influencers that indeed changed their consumer behavior, especially on the YouTube Ria SW account. The difference lies in the reason behavioral variables, namely: digital influencers, products, and reference groups that have a direct impact.
\end{abstract}

\section{Abstrak}

Indonesia memperlihatkan perubahan pola perilaku konsumen modern yang mengandalkan situs media sosial untuk mendapatkan informasi dan review dari produk yang diinginkan. Sejalan dengan hal itu, fenomena yang menarik adalah setelah melalui pre-test yang dilakukan, para mahasiswa Universitas Bunda Mulia yang termasuk dalam generasi milenial mengaku bahwa banyak informasi tempat makan yang menjadi tujuan mereka berasal dari digital influencer yang sering mereka tonton melalui jalur YouTube. Penelitian kualitatif dengan desain studi kasus digunakan sebagai desain penelitian. Hasil penelitian menyatakan ke-19 informan yaitu mahasiswa pada generasi milenial memberikan pernyataan yang sama perihal bahwa digital influencer memang merubah pola perilaku konsumen, termasuk pada promosi produk, pemilihan produk dan keputusan pembelian khususnya pada akun YouTube Ria SW. Pembedanya terletak pada alasannya - variabel perilaku, yaitu: digital influencer, produk, dan grup referensi yang memberikan dampak secara langsung.

*Email korespondensi: gputlia@bundamulia.ac.id

Pedoman Sitasi: Putlia, G \& Thionanda, N.N (2020). Munculnya Digital Influencer Merubah Perilaku Konsumen Pada Promosi Produk, Pemilihan Produk, dan Keputusan Pembelian Generasi Milenial: Studi Pada Akun YouTube Ria SW. Jurnal Manajemen Strategi dan Aplikasi Bisnis, 3(1), 39 50. DOI: https:// doi.org/ 10.36407/jmsab.v3i1.136

\section{JMSAB \\ 39}

Paper type Research paper

Keywords: : consumer behavior, digital influencer, millennial generation, purchasing decisions, promotions.

Received: 21 Jan 2020

Revised: 20 Feb 2020

Accepted: 12 Mar 2020

Online: 15 Mar 2020

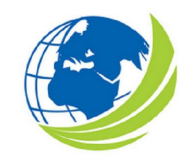

Jurnal Manajemen Strategi dan Aplikasi Bisnis, Vol 3, No.1, Januari-Juni 2020, pp. 39 $-50$ eISSN 2655-237X 


\section{PENDAHULUAN}

Pemasaran merupakan salah satu lini penting dalam bisnis, mulai dari sebuah produk diperkenalkan hingga didistribusikan hingga sampai pada tangan konsumen adalah salah satu tugas dari bagian pemasaran. Saat ini terdapat banyak metode dan cara yang digunakan untuk memasarkan sebuah produk barang atau jasa, namun seiring berjalannya waktu pemasar pun wajib mengubah pola dan taktik pemasaran agar tetap mampu mengikuti perkembangan jaman dan mampu bersaing di pasar bebas dengan para kompetitornya, salah satunya dengan memanfaatkan teknologi pemasaran digital untuk melengkapi strategi konvensional yang telah ada. Berbelanja online telah menjadi salah satu gaya hidup masyarakat modern, seperti data statista.com mengenai global e-retail mencatat pertumbuhan pemasaran dunia yang mencapai 2.3 triliun U.S. dolar pada tahun 2017 dengan pertumbuhan terbesar ada di kawasan asia pasifik yang umumnya ada pada negara-negara seperti Indonesia dan India, diikuti Mexico dan China. Melalui gambar 1, dapat dilihat grafik penjualan ritel dari tahun 2015 hingga perkiraan 2021 mencapai pertumbuhan yang signifikan yaitu rata-rata kenaikan antara $1 \%-3 \%$ setiap tahunnya.

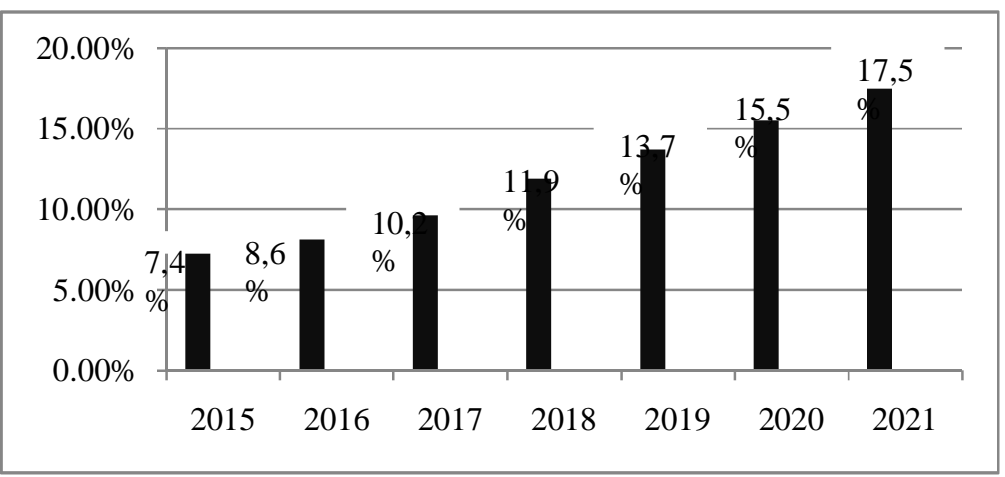

\section{Gambar 1. Data Penjualan E-Commerce secara Global}

Rata-rata transaksi penjualan dilakukan melalui perangkat pribadi seperti smartphone dan tablet, sehingga secara tidak langsung juga dapat meningkatkan jumlah transaksi pertukaran data dan informasi yang tersedia, berdasarkan data dari digitalmarket.asia yang melakukan transaksi online melalui perangkat elektronik dengan jumlah sampel responden pengguna internet sebanyak 72.529 di kawasan asia sendiri penjualan ini di dominasi oleh negara China, namun Indonesia sendiri berada pada peringkat ke 5 sehingga dapat ditarik kesimpulan bahwa pasar penjualan secara online di Indonesia sendiri memiliki prospek yang baik.

Tabel 1. Top 5 Online E-Commerce Market

\begin{tabular}{l|l}
\hline Negara & Rata-Rata Pengguna Internet \\
\hline Cina & $83 \%$ \\
Korea Selatan & $83 \%$ \\
Inggris & $82 \%$ \\
Jerman & $81 \%$ \\
Indonesia & $79 \%$ \\
\hline
\end{tabular}

Sumber: digitalmarket.asia 
Melihat besarnya potensi pasar penjualan secara online di Indonesia secara langsung menunjukkan proses pertukaran data dan informasi yang cepat dan instan ini merubah pola perilaku konsumen modern dengan mengandalkan situs media sosial untuk mendapatkan informasi dan review dari produk yang diinginkan. Dilansir dari mediaindonesia.com, Tetra Pak Index menyatakan kebanyakan konsumen modern yang mengandalkan situs media sosial adalah mereka yang berkisar antara umur 15-20 tahun. Salah satu faktor yang mendasari keberhasilan pemasaran melalui sosial media beberapa tahun belakangan ini adalah munculnya digital influencer. Pada konteks ini, pihak yang disebut sebagai digital influencer memiliki popularitas tinggi dan tidak selalu berasal dari kalangan artis atau public figure tetapi memiliki akun dengan banyak follower. Penggunaan metode ini akan membuat sang influencer memerankan sebagai pembeli atau pengguna suatu merek yang mampu merepresentasikan tentang hal-hal yang dimiliki merek sehingga dapat meningkatkan tingkat penjualan dari merek produk tersebut.

Dirangkum dari Kompas.com, penelitian yang dilakukan We Are Social - perusahaan media asal Inggris yang bekerjasama dengan Hootsuite menyatakan rata-rata orang Indonesia menghabiskan 3 jam 23 menit dalam sehari untuk mengakses media sosial. Platforms media sosial yang paling banyak digunakan di Indonesia dapat kita lihat rinciannya pada gambar 2 sebagai berikut:

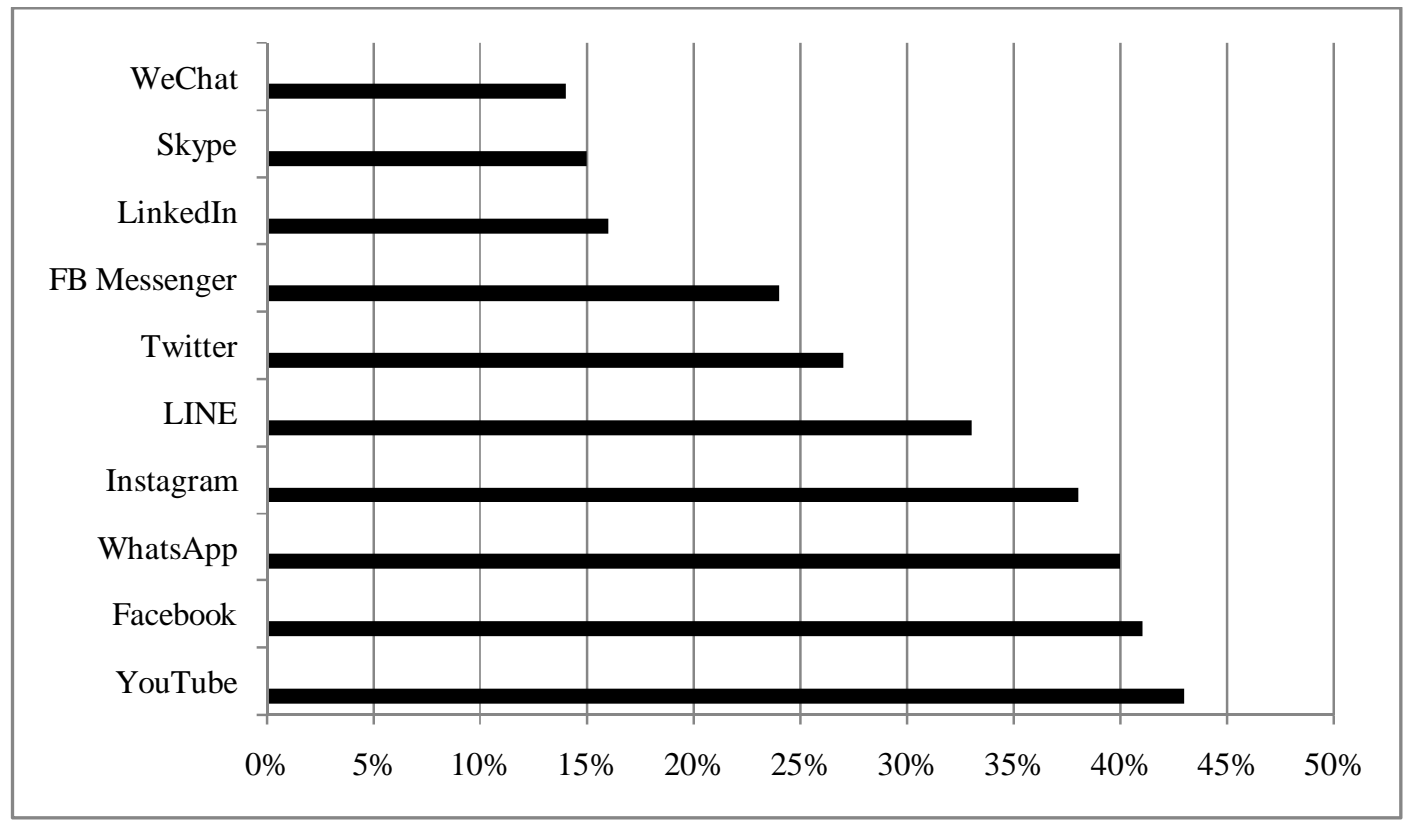

Gambar 2. Platforms Media Sosial Aktif di Indonesia 2018

Dari data di atas, YouTube memimpin dengan angka pengguna sebanyak 43\% yang diikuti Facebook 41\% dan WhatsApp 40\%. Berikutnya ada Instagram dengan pengguna sebanyak 38\%, dan LINE $33 \%$. Twitter berada pada posisi berikutnya dengan pengguna sebanyak $27 \%$, sedangkan FB Messenger sebanyak 24\%. LinkedIn dengan 26\% pengguna, Skype 15\% pengguna dan di posisi terakhir ada WeChat dengan $14 \%$ pengguna. Sejalan dengan hal itu, pre-test yang dilakukan kepada 43 mahasiswa semester 2 Universitas Bunda Mulia kampus Serpong untuk mengetahui siapa digital influencer yang memiliki pengaruh paling besar dalam hidup mereka menuai hasil serupa. Hasil yang didapat yaitu mengindikasikan bahwa platforms media sosial yang paling sering mereka gunakan adalah YouTube. Hal tersebut dapat dilihat dalam rincian tabel 2 berikut: 
Tabel 2. Hasil Pre-test 43 Mahasiswa UBM Kampus Serpong

\begin{tabular}{l|l}
\hline Digital Influencer & Jumlah Mahasiswa \\
\hline Ria Sukma Wijaya & 23 orang \\
Devienna Setiawan & 9 orang \\
Kenneth Chandra \& Gratiana Lianto & 5 orang \\
Sunny Dahye & 3 orang \\
Magdalena Fridawati & 3 orang \\
\hline
\end{tabular}

Sumber: data primer, Peneliti 2019

Ria Sukma Wijaya atau yang lebih dikenal dengan sebutan Ria SW dalam kanal YouTube merupakan salah satu YouTuber paling populer di Tanah Air. Konten yang diunggahnya selalu laris hingga saat ini telah mencapai 2,4 juta subcriber. Tak tanggung, luar negeri pun Ria sambangi demi membuat konten menarik YouTubenya mengenai makanan dan travelling (https://www.idntimes.com). Fenomena yang menarik adalah melalui pre-test yang telah dilakukan, para mahasiswa yang termasuk dalam generasi milenial mengaku bahwa banyak informasi tempat makan yang menjadi tujuan mereka berasal dari digital influencer yang sering mereka tonton melalui jalur YouTube. Dengan demikian, penelitian ini ingin mengulas lebih dalam mengenai "Munculnya Digital Influencer Merubah Perilaku Konsumen pada Promosi Produk dan Keputusan Pembelian Generasi Milenial (Studi Kasus Akun YouTube Ria SW).

\section{KAJIAN PUSTAKA}

Kotler (2018) mendefinisikan pemasaran sebagai proses di mana perusahaan melibatkan pelanggan, membangun hubungan baik dengan pelanggan, dan menciptakan nilai untuk pelanggan, sehingga dapat mendapatkan nilai/ umpan balik yang baik dari pelanggan dalam rangka untuk meningkatkan profit dan ekuitas pelanggan. Pada saat ini, teknologi memberikan pengaruh sangat besar sehingga e-marketing pun berkembang pesat. E-marketing (electronic marketing) menurut Tjiptono (2016), adalah proses strategik, mengembangkan, mendistribusikan, mempromosikan, dan menetapkan harga barang dan jasa kepada pasar sasaran melalui internet atau alat-alat digital seperti smartphone dan tablet.

E-marketing menjadi salah satu cara yang dinilai efektif dan efisien, terutama untuk melakukan belanja online baik produk digital seperti perangkat lunak, video, musik atau sejenisnya maupun produk non-digital. Besarnya potensi pasar penjualan secara online di Indonesia secara langsung menunjukkan proses pertukaran data dan informasi yang cepat dan instan ini merubah pola perilaku konsumen modern dengan mengandalkan situs media sosial untuk mendapatkan informasi dan review dari produk yang diinginkan. Dilansir dari mediaindonesia.com, Tetra Pak Index menyatakan kebanyakan konsumen modern yang mengandalkan situs media sosial adalah mereka yang berkisar antara umur 15-20 tahun. Salah satu faktor yang mendasari keberhasilan pemasaran melalui media sosial beberapa tahun belakangan ini adalah munculnya digital influencer.

\section{Digital Influencer}

Perkembangan teknologi membuat media promosi semakin bertambah, salah satunya melalui media internet. Menggunakan media tersebut, perusahaan tidak membutuhkan banyak biaya untuk mempromosikan produk. Jangkauan pun lebih luas. Kotler dan Keller (2016) menyatakan bahwa sosial media adalah: "Social media are a means for consumers to share text, images, audio, and video information with each other and with companies, and vice versa." Artinya, sosial media adalah sarana bagi konsumen untuk berbagi informasi teks, gambar, audio, dan video dengan satu sama lain dan dengan perusahaan dan sebaliknya.

Senft (2013) memperkenalkan terminologi "micro-celebrity" yang berarti sebuah cara baru dalam kegiatan online dimana seseorang melakukan berbagai macam cara untuk meningkatkan popularitasnya di internet dengan menggunakan berbagai teknologi seperti video, blog, dan situs jejaring sosial. Marwick (2013) sejalan dengan menyatakan micro-celebrity juga dapat dipahami sebagai suatu praktik dimana seseorang dianggap sebagai basis penggemar (fanbase), yang 
kepopulerannya dikelola melalui manajemen penggemar, dan presentasi diri seseorang secara hatihati dikonstruksi sebagai bahan konsumsi orang lain.

Kesamaan diantara terminologi micro-celebrity dengan digital influencer adalah penggunaan platform media sosial dalam membangun fanbase/ followers. Dalam konteks pemasaran dan promosi, para digital influencer ini menjalankan fungsi promosi. Survey statistik majalah Forbes mengungkapkan bahwa 92\% konsumen lebih percaya kepada influencer dibandingkan iklan atau cara endorse tradisional melalui selebriti. Maka tak aneh jika digital influencer ini dapat menjalankan fungsi promosi lebih efektif.

\section{Perilaku Konsumen}

Perilaku konsumen perlu dipahami perusahaan agar dapat memasarkan produknya dengan baik. Seorang konsumen pada dasarnya memiliki banyak perbedaan, namun disisi lain memiliki banyak kesamaan sehingga hal tersebut perlu menjadi perhatian pemasar. Mulyati et al (2016) menyatakan bahwa perilaku konsumen adalah kegiatan-kegiatan individu yang secara langsung terlibat dalam mendapatkan dan menggunakan barang atau jasa yang termasuk didalamnya proses pengambilan keputusan pada persiapan dan penentuan kegiatan-kegiatan tersebut. Kotler dan Keller (2016) menyatakan perilaku konsumen adalah: "Consumer behavior is the study of how individuals, groups, and organizations select, buy, use, and dispose of goods, service, ideas, or experiences to satisfy their needs and wants.". Dari definisi yang ada, dapat ditarik kesimpulan bahwa perilaku konsumen adalah tentang bagaimana individu, kelompok, dan organisasi memilih, membeli, menggunakan dan bagaimana barang, jasa, ide, atau pengalaman untuk memuaskan kebutuhan dan keinginan.

Promosi Produk

Simamora (2003) memberikan definisi promosi adalah segala bentuk komunikasi yang digunakan untuk menginformasikan (inform), membujuk (persuade), atau mengingatkan orang-orang tentang produk yang dihasilkan organisasi, individu maupun rumah tangga. Promosi dibentuk untuk memperlancar komunikasi perusahaan dengan konsumen. Maka dari itu promosi dirancang semenarik mungkin untuk menjangkau masyarakat luas melalui bermacam-macam media.

Keputusan Pembelian

Kotler dan Keller (2016) menyatakan bahwa keputusan pembelian adalah: "Buying decision process all the experiences in learning, chooshing, using, and even disposing of a product." Artinya, keputusan pembelian adalah semua pengalaman dalam pembelajaran, pemilihan, penggunaan, dan bahkan pembuangan produk. Sedangkan menurut Suharto (2016) keputusan pembelian adalah semua tindakan yang menentukan semua pilihan yang ada untuk dipilih salah satu diantaranya, dengan melalui tahap pengenalan, pencarian informasi, penilaian alternatif, keputusan membeli, perilaku setelah pembelian. Menurut Kotler dan Keller (2012) proses keputusan pembelian melalui lima tahap, yaitu: pengenalan kebutuhan, pencarian informasi, pengevaluasian alternatif, keputusan pembelian, dan pasca pembelian.

\section{Generasi Milenial}

Generasi Y dikenal dengan sebutan generasi milenial atau milenium. Ungkapan generasi Y mulai dipakai pada editorial koran besar Amerika Serikat pada Agustus 1993. Oblinger \& Oblinger (2005) menyatakan bahwa generasi milenial dikenal dengan sebutan Gen Y atau NetGen adalah generasi yang lahir pada tahun 1981-1995. Generasi ini banyak menggunakan teknologi komunikasi instan seperti email, SMS, instant messanging dan sosial media, dengan kata lain generasi Y adalah generasi yang tumbuh pada era internet booming (Lyons, 2013). Lebih lanjut, Lyons (2013) mengungkapkan ciri-ciri dari generasi Y adalah: karakteristik masing-masing individu berbeda, tergantung dimana ia dibesarkan, strata ekonomi, dan sosial keluarganya, pola komunikasinya sangat terbuka dibanding generasi-generasi sebelumnya, pemakai sosial media yang fanatik dan kehidupannya sangat terpengaruh dengan perkembangan teknologi, lebih terbuka dengan pandangan politik dan ekonomi, sehingga mereka terlihat sangat reaktif terhadap perubahan lingkungan yang terjadi di sekelilingnya, memiliki perhatian yang lebih terhadapnya. Menurut Yuswohady (2017) menyatakan bahwa generasi milenial (millennial generation) adalah generasi yang lahir dalam rentang waktu awal tahun 
1981 hingga tahun 2000. Generasi ini sering disebut sebagai Gen-Y, Net Generation, Generation WE, Boomerang Generation, Peter Pan Generation, dan lain-lain.

\section{METODE}

\section{Desain Penelitian}

Desain penelitian yang digunakan dalam penelitian ini adalah studi kasus. Penelitian studi kasus merupakan pendekatan kualitatif yang penelitinya mengeksplorasi kehidupan-nyata, lebih lanjut Creswell (2015) menyatakan termasuk sistem terbatas kontemporer (kasus) melalui pengumpulan data yang detail dan mendalam yang melibatkan beragam sumber informasi, dan melaporkan deskripsi kasus dan tema kasus.

\section{Populasi dan Sampel}

Penelitian kualitatif dilakukan untuk menjelaskan fenomena dengan sedalam-dalamnya melalui pengumpulan data sedalam-dalamnya. Dengan demikian, penelitian ini tidak mengutamakan besarnya sampel. Jika data yang terkumpul sudah mendalam dan bisa menjelaskan fenomena yang diteliti, maka tidak perlu mencari informan lainnya. Menurut Kriyantono (2009), penelitian kualitatif lebih menekankan pada persoalan kedalaman (kualitas) data bukan banyaknya (kuantitas) data.

\section{Pengembangan Instrumen}

Pengembangan instrumen pada penelitian kualitatif mengandalkan triangulasi. Triangulasi adalah teknik pemeriksaan keabsahan data yang memanfaatkan sesuatu yang lain. Di luar data itu untuk keperluan pengecekan atau sebagai pembanding terhadap data itu. Secara lebih spesifik triangulasi yang digunakan dalam penelitian ini adalah triangulasi sumber. Triangulasi sumber yaitu membandingkan dan mengecek balik derajat kepercayaan suatu informasi yang diperoleh melalui waktu dan alat yang berbeda dalam penelitian kualitatif. Hal ini dapat dicapai dengan jalan/ cara salah satunya membandingkan hasil wawancara narasumber atau informan satu dengan narasumber/ informan penelitian yang lain (Moleong, 2007).

\section{Teknik Analisis}

Kriyantono (2009), menyatakan metode yang digunakan adalah perbandingan tetap karena dalam analisis data secara tetap membandingkan kategori dengan kategori lainnya. Pertama, reduksi data: (1) Identifikasi satuan (unit). Awalnya diidentifikasi adanya sesuatu bagian terkecil yang ditemukan dalam data yang memiliki makna bila dikaitkan dengan fokus dan masalah penelitian; (2) Sesudah satuan diperoleh, selanjutnya adalah membuat koding. Membuat koding berarti memberikan kode pada setiap "satuan", agar supaya tetap dapat ditelusuri datanya/ satuannya, berasal dari sumber mana. Kedua, kategorisasi sintesisasi: (1) Kategori tidak lain adalah satu tumpukan dari seperangkat tumpukan yang disusun atas dasar pikiran, intuisi, pendapat, kriteria tertentu. (2) Mengelompokkan jawaban yang ada ke dalam bagian-bagian tertentu yang secara jelas berkaitan. (3) Merumuskan aturan yang menetapkan inklusi setiap bagian kategori. (4) Menjaga agar setiap kategori yang telah disusun satu dengan lainnya mengikuti prinsip. Ketiga, sintesa, yaitu : (1) mensintesiskan berarti mencari kaitan antara satu kategori dengan kategori lainnya. (2) Kaitan satu kategori dengan kategori lainnya diberi nama/label lagi. Ke-empat, menyusun hipotesis kerja yaitu menyusun Hipotesis Kerja dilakukan dengan jalan merumuskan suatu pernyataan yang proporsional. Hipotesis kerja ini merupakan teori substantif, yaitu teori yang berasal dan masih terkait dengan data, dan bahwa hipotesis kerja itu hendaknya terkait dan sekaligus menjawab pertanyaan penelitian. 


\section{HASIL DAN PEMBAHASAN}

Kriyantono (2009), menyatakan bahwa penelitian kualitatif lebih menekankan pada persoalan kedalaman (kualitas) data bukan banyaknya (kuantitas) data. Jika data yang terkumpul sudah mendalam dan bisa menjelaskan fenomena yang diteliti, maka tidak perlu mencari informan lainnya. Berpedoman dengan hal tersebut, maka tercapailah data jenuh dengan terkumpul sejumlah 19 orang mahasiswa dari beberapa universitas di wilayah Alam Sutera yang bersedia untuk menjadi informan berkenaan dengan masalah yang tengah diteliti. Profil informan dapat dilihat lebih rinci pada Tabel 1.3.:

Tabel 3. Profil Informan

\begin{tabular}{lccc}
\hline Informan & Universitas & $\begin{array}{c}\text { Jumlah } \\
\text { Nonton }\end{array}$ & Alasan \\
\hline Informan 1 & UBM & $6 \times /$ bulan & Grup Referensi \\
\hline Informan 2 & UBM & $15 \times /$ bulan & Digital Influencer \\
\hline Informan 3 & UBM & $7 \times /$ bulan & Digital Influencer \\
\hline Informan 4 & BINUS & $5 \times /$ bulan & Produk \\
\hline Informan 5 & BINUS & $4 \times /$ bulan & Grup Referensi \\
\hline Informan 6 & BINUS & $13 \times /$ bulan & Digital Influencer \\
\hline Informan 7 & UBM & $8 \times /$ bulan & Digital Influencer \\
\hline Informan 8 & UBM & $7 \times /$ bulan & Produk \\
\hline Informan 9 & UBM & $25 \times /$ bulan & Digital Influencer \\
\hline Informan10 & SGU & $8 \times /$ bulan & Digital Influencer \\
\hline Informan11 & UBM & $7 \times /$ bulan & Digital Influencer \\
\hline Informan12 & UBM & $12 \times /$ bulan & Digital Influencer \\
\hline Informan13 & UBM & $6 \times /$ bulan & Produk \\
\hline Informan14 & BINUS & $10 \times /$ bulan & Produk \\
\hline Informan15 & BINUS & $17 \times /$ bulan & Digital Influencer \\
\hline Informan16 & UBM & $7 \times /$ bulan & Digital Influencer \\
\hline Informan17 & UBM & $11 \times /$ bulan & Grup Referensi \\
\hline Informan18 & SGU & $9 \times /$ bulan & Digital Influencer \\
\hline Informan19 & SGU & $4 \times /$ bulan & Produk \\
\hline
\end{tabular}

Sumber : dokumentasi peneliti, 2019

Keseluruhan data yang didapat dari 19 informan seperti yang tertera di atas mengusung beberapa judul video Ria SW adalah sebagai berikut: (1) My Top 3 Snacks (4,9 juta $\times$ ditonton); (2) Jajanan Kolong Jembatan Busway (6,5 juta $\times$ ditonton); (3) Spiciest Food in Singapore \#2 (7,9 juta $\times$ ditonton); dan (4) Korean Street Food \#3 (23 juta $\times$ ditonton). Terlihat bahwa secara keseluruhan informan berasal dari 3 kampus yang berada di wilayah Alam Sutera, yaitu UBM, BINUS, dan SGU dimana secara dominan para informan dapat dikatakan cukup sering menonton video kuliner Ria SW meskipun dilatarbelakangi alasan yang berbeda antara yang satu dengan lainnya. Setelah semua data 
didapatkan, yang harus dilakukan berikutnya adalah olah data. Secara terperinci bisa dilihat pada Tabel 4 dan Tabel 5.:

Tabel 4. Pengklasteran Kategori berkenaan Persoalan Penelitian

\section{Munculnya Digital Influencer Merubah Perilaku Konsumen pada Promosi Produk, Pemilihan Produk, dan Keputusan Pembelian Generasi Milenial (Studi Kasus Akun YouTube Ria SW)}

\begin{tabular}{l|l|l|l|}
\hline \multicolumn{4}{c}{ Variabel } \\
\hline \multicolumn{1}{c}{ Perilaku Konsumen } & \multicolumn{1}{c}{ Promosi Produk } & \multicolumn{1}{c}{ Pemilihan Produk } & \multicolumn{1}{c}{ Keputusan Pembelian } \\
\hline \begin{tabular}{llll} 
1. Sangat merubah & 1. Sangat merubah & 1. Sangat merubah & 1. Sangat merubah \\
2. Merubah & 2. Merubah & 2. Merubah & 2. Merubah \\
3. Cukup merubah & 3. Cukup merubah & 3. Cukup merubah & 3. Cukup merubah \\
4. Biasa & 4. Biasa & 4. Biasa & 4. Biasa \\
& & & \\
\hline
\end{tabular}
\end{tabular}

Munculnya Digital Influencer Merubah Perilaku Konsumen pada Promosi Produk, Pemilihan Produk, dan Keputusan Pembelian Generasi Milenial (Studi Kasus Akun YouTube Ria SW)

\begin{tabular}{|c|c|c|}
\hline \multicolumn{3}{|c|}{ Alasan } \\
\hline Digital Influencer & Produk & Grup Referensi \\
\hline $\begin{array}{l}\text { 1. Sangat suka } \\
\text { 2. Suka } \\
\text { 3. Cukup suka } \\
\text { 4. Biasa }\end{array}$ & $\begin{array}{l}\text { 1. Korean Street Food \#3 } \\
\text { 2. Spiciest Food in Singapore \#2 } \\
\text { 3. Jajanan Kolong Jembatan Busway } \\
\text { 4. My Top } 3 \text { Snacks }\end{array}$ & $\begin{array}{l}\text { 1. Teman } \\
\text { 2. Keluarga } \\
\text { 3. Relasi }\end{array}$ \\
\hline
\end{tabular}

Sumber: Peneliti, 2019

Tabel 5. Klaster Kategori, Pola, dan Konsep

\begin{tabular}{|c|c|c|}
\hline $\begin{array}{l}\text { Persoalan } \\
\text { Penelitian }\end{array}$ & $\begin{array}{c}\text { Klaster Kategori } \\
\text { Jawaban }\end{array}$ & Pola dan Konsep \\
\hline $\begin{array}{lr}\text { Apakah munculnya } \\
\text { digital influencer } \\
\text { merubah perilaku } \\
\text { konsumen } r \text { pada } \\
\text { promosi produk, } \\
\text { pemilihan produk } \\
\text { dan keputusan } \\
\text { pembelian generasi } \\
\text { milenial } & \text { (Studi } \\
\text { Kasus r } & \text { Akun } \\
\text { YouTube Ria SW) }\end{array}$ & $\begin{array}{l}\text { 1. Perilaku Konsumen } \\
\text { 2. Promosi Produk } \\
\text { 3. Pemilihan Produk } \\
\text { 4. Keputusan } \\
\text { Pembelian }\end{array}$ & $\begin{array}{l}\text { Generasi milenial yakni mahasiswa selaku } \\
\text { informan menyatakan bahwa terjadi } \\
\text { perubahan pola dalam melakukan keputusan } \\
\text { pembelian mereka dipengaruhi oleh beberapa } \\
\text { faktor, diantaranya: perilaku konsumen yang } \\
\text { mana secara lebih jauh dapat diidentifikasi } \\
\text { beberapa alasannya adalah digital influencer, } \\
\text { produk, dan grup referensi yang memberikan } \\
\text { dampak secara langsung; promosi produk, } \\
\text { serta pemilihan produk. Sehingga, dampak } \\
\text { keberadaan digital influencer memang sangat } \\
\text { dirasakan di kalangan konsumen terutama } \\
\text { generasi milenial. }\end{array}$ \\
\hline
\end{tabular}

\section{Sumber: Peneliti, 2019}

Hasil akhir setelah olah data menunjukkan bahwa dari ke-19 informan memiliki pernyataan yang sama perihal bahwa digital influencer memang merubah pola perilaku konsumen mereka termasuk pada promosi produk, pemilihan produk dan keputusan pembelian. Pada setiap jawaban informan 
yang membedakan hanyalah alasannya saja, dapat dilihat pada uraian berikut. Informan ke-5 dan ke19 merupakan informan dengan jumlah nonton paling sedikit dibandingkan para informan yang lainnya yaitu sebanyak $4 \times /$ bulan, namun jika ditelusuri lebih lanjut, hal itu dapat dikatakan 'cukup' mengingat channel YouTube yang ditonton adalah sama yaitu channel YouTube Ria SW. Jika kita ilustrasikan pembagian waktu nonton setiap minggu, maka informan ke-5 dan ke-19 setiap minggu menonton $1 \times /$ minggunya. Berikut pernyataan informan ke-5:

"Saya itu suka makan, cuma dibilang hobi juga sebenarnya enggak. Kenal Ria SW dari temen sih waktu itu lagi pada ngomongin terus saya tanya. Udah deh, sejak itu ya lumayan sering nonton. Seenggaknya seminggu sekali saya selalu cek, kalau belum ada notif baru kadang saya nonton ulang beberapa video lamanya. Hehe..."

Sejalan dengan hal itu, informan ke-19 menyatakan hal serupa:

"Setidaknya seminggu sekali saya selalu nonton Ria SW. Emm..., kayaknya apa yang dia makan hampir semuanya saya sudah coba. Saya cari inspirasi makanan dari dia sih, meskipun jujur ya saya ikutin juga influencer lain tapi Ria SW is number one."

Berbeda dengan informan ke-12 yang menonton channel YouTube Ria SW 12×/ bulan. Jika kita ilustrasikan pembagian waktu nonton setiap minggu, maka informan ke-12 setiap minggu menonton setidaknya $3 \times /$ minggunya. Berikut pernyataan informan ke-12:

“Tahu Ria SW itu justru malah pas gak sengaja nonton channel YouTube malesbanget.com, dari situ udah sreg banget sama pembawaannya yang apa adanya mulai dari cara ngomong sampai outfitnya. Terus mulai ikutin sampai dia bikin channel sendiri dan topik dia gue banget! Makan dan traveling! Lanjut terus deh sampai sekarang nontonin. Pokoknya kalau mau cobain makanan cek dulu, Ria udah pernah review belum ya. Kalau review bagus langsung cap cus, tapi kalau review dari dia jelek apalagi harga mehong ya gue pikir-pikir lagi."

Sejalan dengan informan ke-12, informan ke-6 yang menonton channel YouTube Ria SW 13×/ bulan. Jika kita ilustrasikan pembagian waktu nonton setiap minggu, maka informan ke-13 setiap minggu menonton setidaknya 3-4×/ minggunya. Berikut pernyataan informan ke-13:

"Pokoknya kalau urusan makan ingetnya Ria SW! Jujur ya, selain menghibur channel dia merupakan salah satu solusi atau penunjuk arah terbaik disaat-saat mau makan atau ngemil. Gue sendiri udah ga itung deh ada berapa kali kesempatan yang mana gue makan (sendiri, sama keluarga, temen, dll) yang diawali dengan searching dulu channel Ria SW di YouTube. Mulai dari makanan mahal sampe murah dia cobain, di restoran mewah sampai di kolong jembatan busway!"

Informan ke-9 merupakan informan dengan jumlah nonton paling banyak dibandingkan para informan yang lainnya yaitu sebanyak $25 \times$ bulan. Jika diilustrasikan pembagian waktu nonton setiap minggu, maka informan ke-9 setiap minggu menonton 6-7x/minggunya. Berikut pernyataan informan ke-9:

"Ria SW gokil sih! Gue ga ngerti harus ngomong apalagi. Dianya bikin gue jadi kecanduan atau guenya yang ga kuat sampe jadi kecanduan ya? Haha... Pokoknya semua makanan, minuman, sampe ke camilan yang Ria makan gue kejar buat cari terus cobain. Yang belum kesampean makan makanan yang ke luar-luar negeri, namanya juga masih uang saku dari ortu. Besok kalau sudah kerja sendiri bolehlah ya gue cobain makanan Ria SW yang di luar-luar negeri."

Dari uraian di atas, terbukti bahwa digital influencer memang merubah pola perilaku konsumen mereka termasuk pada promosi produk, pemilihan produk dan keputusan pembelian. Pembedanya 
terletak pada alasannya, yaitu: digital influencer, produk, dan grup referensi yang memberikan dampak secara langsung.

\section{KESIMPULAN}

Berdasarkan hasik sintesa dan pembahasan dapat dinyatakan bahwa seluruh informan yaitu mahasiswa pada generasi milenial memberikan pernyataan yang sama perihal bahwa digital influencer memang merubah pola perilaku konsumen mereka termasuk pada promosi produk, pemilihan produk dan keputusan pembelian khususnya pada akun YouTube Ria SW. Pembedanya terletak pada alasannya - variabel perilaku, yaitu: digital influencer, produk, dan grup referensi yang memberikan dampak secara langsung. Informan ke-9 yang merupakan informan dengan jumlah nonton paling banyak dibandingkan para informan yang lainnya yaitu sebanyak $25 \times /$ bulan. Berikut pernyataan informan ke-9:

"Ria SW gokil sih! Gue ga ngerti harus ngomong apalagi. Dianya bikin gue jadi kecanduan atau guenya yang ga kuat sampe jadi kecanduan ya? Haha... Pokoknya semua makanan, minuman, sampe ke camilan yang Ria makan gue kejar buat cari terus cobain. Yang belum kesampean makan makanan yang ke luar-luar negeri, namanya juga masih uang saku dari ortu. Besok kalau sudah kerja sendiri bolehlah ya gue cobain makanan Ria SW yang di luar-luar negeri."

Dari kesimpulan yang ada telah menjawab bahwa "Munculnya Digital Influencer Merubah Perilaku Konsumen pada Promosi Produk dan Keputusan Pembelian Generasi Milenial (Studi Kasus Akun YouTube Ria SW) adalah positif.

\section{Implikasi Praktis / Teoritis}

Konsumen semakin hari semakin terpengaruh dengan 'digital influencer' yang seharusnya sudah menjadi catatan sendiri bagi para pemasar bahwa cara promosi pun sudah mulai bergeser ke ranah digitalisasi. Jika dulu kita mengenal brand ambasador, kini digital influencer mampu menarik perhatian pasar secara luas.

\section{Keterbasan dan Saran}

Ada pepatah mengatakan "tak ada yang sempurna di dunia", begitu pula dengan penelitian ini. Adapun keterbatasan yang dirasakan peneliti, yaitu mengenai waktu pengumpulan data. Waktu yang terbatas menyebabkan informasi yang didapat kurang mendalam, meski demikian semua pertanyaan tetap tersampaikan dan masalah penelitian terjawab. Akhirnya, saran untuk penelitian ini bahwa kedepannya dapat dilakukan penelitian serupa dengan menambahkan beberapa variabel yang lebih relevan mengingat persaingan pemasaran di era digital saat ini tengah berkembang pesat.

\section{REFERENSI}

Creswell, J., W., (2015). Penelitian Kualitatif \& Desain Riset - Memilih di Antara Lima Pndekatan. Cetakan 1.

Kotler, P., (2018). Principles of Marketing: Global Edition. 17th. United Kingdom: Pearson

Kotler, P., dan Keller, K, L. (2012). Manajemen Pemasaran. Edisi 12. Jakarta: Erlangga .(2016). Marketing Management, 15th Edition, Pearson Education,Inc.

Kriyantono, R. (2009). Teknik Praktis Riset Komunikasi. Perdana Media Group.

Lyons, S., (2013). Generation Y's Psychological Traits, Entitlement, and Career Expectations. Canada: University of Guelph.

Marwick, A., E. (2013). Status update. Celebrity, Publicity, and Branding. New Haven: Yale University Press.

Moleong, L., J. (2007). Metodologi Penelitian Kualitatif. Bandung: PT. Remaja Rosdakarya Offset. . (2011). Metodologi Penelitian Kualitatif. Edisi Revisi. Bandung: PT Remaja Rosdakarya. 
Mulyati, H. (2016). Hubungan Pola Konsumsi Natrium dan Kalium serta Aktifitas Fisik dengan Kejadian Hipertensi pada Pasien Rawat Jalan di RSUP DR. Wahidin Sudirohusodo Makassar. Media Gizi Masyarakat Indonesia. Vol.1. No.1. September2011. Hal: 46-51.

Oblinger, D., and Oblinger, J. (2005). Is It Age or IT: First Steps towards Understanding the Netgeneration. In D. Oblinger, \& J. Oblinger (Eds.), Educating the Net Generation (pp. 2.1-2.20).

Senft,T., M. (2013). Microcelebrity and the Branded Self. In: J.Hartley, J.Burgess, and A.Bruns, eds. A Companion to New Media Dynamics. Chichester: Wiley-Blackwell.

Simamora, H., (2003). Manajemen Pemasaran Internasional. Jilid 2,Jakarta: Salemba Empat

Suharto, D., G. (2016). Membangun Kemandirian Desa. Yogyakarta: Pustaka Pelajar.

Tjiptono, F. (2016). Pemasaran: Esensi dan Aplikasi. Yogyakarta: Andi.

Yuswohady, H., I. (2017). Gen M \#GENERATIONMUSLIM “Islam Itu Keren”. Yogyakarta: PT Bentang Pustaka.

http:// www.digitalmarket.asia/ data-pick-day-china-leads-online-shopping/, diakses 2019

htttps:/ / www.statista.com/ statistics/534123/ e-commerce-share-of-retail-sales-worldwide/ , diakses 2019

https:// mediaindonesia.com/read/ detail/182896-tetra-pak-index-2018-paparkan-tren-belanjakonsumen-di-indonesia, diakses 2019

https:// tekno.kompas.com/read/2018/ 03/01/10340027/ riset-ungkap-pola-pemakaian-medsosorang-indonesia, diakses 2019

https:/ / www.idntimes.com/ hype/ entertainment/ mahesti-dita/ fakta-ria-sw-food-vlogger-kecedengan-jutaan-viewers-c1c2/ full, diakses 2019

\section{PROFIL PENULIS}

Grace Putlia adalah dosen Prodi Manajemen Fakultas Ilmu Sosial dan Humaniora Universitas Bunda Mulia dengan pengalaman mengajar pemasaran seperti manajemen pemasaran, pemasaran internet, pemasaran ritel, seni bisnis ritel, waralaba ritel, pencegahan kerugian, manajemen penjualan, dan riset pemasaran di tingkat sarjana. Penulis memiliki ketertarikan pada penelitian bidang pemasaran, dan bisnis ritel. Grace Putlia adalah penulis koresponden dapat dihubungi di: gputlia@budamulia.ac.id

Nataya Niken Thioanda adalah mahasiswi aktif semester empat Program Studi Manajemen di Universitas Bunda Mulia Kampus Serpong. 
Jurnal Manajemen Strategi dan Aplikasi Bisnis, 3(1), 39-50

Grace Putlia \& Nataya Niken Thionanda. Digital influence, generasi milenial

This page intention to blank... 